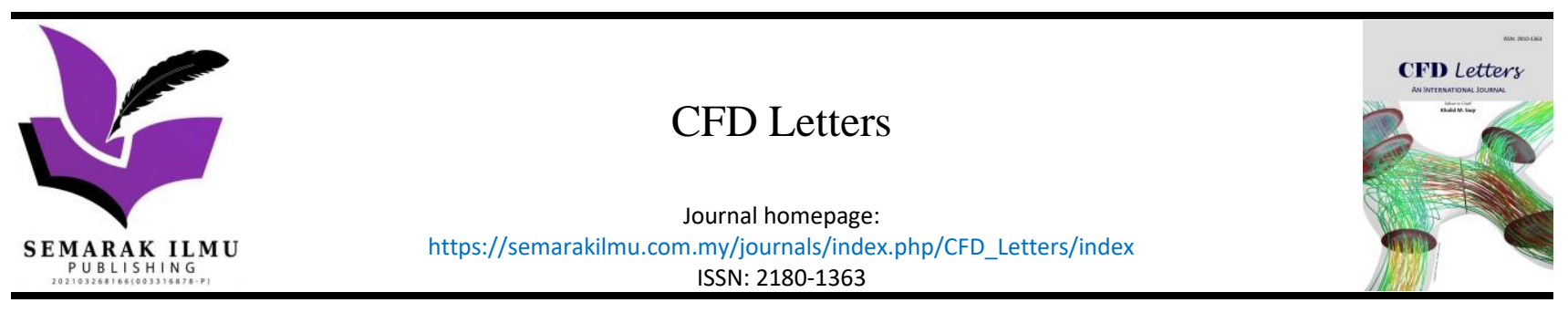

\title{
Elevator Tab Model and Aerodynamic Hinge Moment Variation Effect on Flutter Analysis of a Small Commuter Aircraft
}

\author{
Muchamad Bayu Sakti Pratama ${ }^{1,2}$, Erwin Sulaeman ${ }^{3,}{ }^{,}$, Kezia Grace Walesasi ${ }^{1}$, Ari Legowo $^{4}$ \\ Directorate of Technology and Development, Indonesian Aerospace, Bandung, West Java, Indonesia \\ Akademi Teknologi Aeronautika Siliwangi, Bandung, West Java, Indonesia \\ Department of Mechanical Engineering, International Islamic University Malaysia, 53100 Kuala Lumpur, Malaysia \\ Aviation Engineering Division, Higher Colleges of Technology, Abu Dhabi, United Arab Emirates
}

\section{Article history:}

Received 3 October 2021

Received in revised form 1 December 2021

Accepted 2 December 2021

Available online 7 January 2022
Keywords:

Flutter; Balance-tab; Aeroelasticity; Trimtab
Investigation of flutter instability analysis is an important process during design phase and certification of an aircraft. Without proper analysis, the effect of modification at later stage of design process could come at high cost and risk. The present work examines detailed elevator tab model which could result in a more critical tab flutter speed. The present investigation of aerodynamic hinge moment variation effect on flutter analysis also shows a significant decrease in the flutter speeds. Three configurations involving elevator trim tab and balance tab fixed/free mechanism are investigated. Investigation of flutter sensitivity to tab rotational frequency and tab bending/torsion frequency was performed to determine the minimum tab rotational frequency requirement, so that it can be used as reference in design process. Variation of Mach number (for Configuration 1 ) and elevator aerodynamic hinge moment (all configurations) are performed. It is found that the aerodynamic variation takes effect when the mode involves both trim and balance tabs and tab elastic modes (e.g., tab torsion). It is found also that the most critical flutter case is for Configuration 3 where the trim and balance tabs are not fixed (independent). The result suggests that control surface tabs need to be modelled from the early design process, so that if any critical flutter appears and needs to be responded by a change in design, it can be implemented earlier and therefore avoid any costly risk.

\section{Introduction}

Flutter is an aeroelastic phenomenon (particularly on aircraft) that, if occurred, can cause a structural failure and may lead to a catastrophic event [1-15]. A number of aeroelastic accidents and incidents were recorded throughout history, which in some cases involves tab flutter [16]. Flutter is classified as dynamic aeroelasticity phenomenon which cause instability due to unfavorable coupling of aerodynamic, inertial, and elastic forces. Flutter involves an oscillatory effect on structure that extracts the energy from the air stream, this means that it will involve unsteady aerodynamics forces

\footnotetext{
* Corresponding author.

E-mail address: esulaeman@iium.edu.my (Erwin Sulaeman)
} 
and moments during oscillation. The oscillatory movement on flutter is a self-excited vibration that involves two or more modes of vibration that couples in an unfavorable manner [15].

The practice of flutter in the industry is focused on two things, firstly is to give the necessary feedbacks and inputs throughout the design process, and secondly is to achieve the required certification. The challenge of flutter evaluation is to keep up with the pace and needs of the design process [4]. The problem is, for aeroelastic analysis (particularly flutter) it will require significant flow time and resources due to the various data inputs and modelling involved in the analysis. It is often to implement different analytical model between flutter and stress analysis, and on some projects, it can also be different analytical model between flutter, dynamic flight loads, and static loads. Thus, throughout the design process, it is common to use a simpler model during preliminary design and then gradually add more details to the model up to the detail design/final design process. Maintaining the models to be consistently updated with each other is very difficult, and can potentially result in different adjustment application to different models.

The study of the effect of tab modelling variation for numerical flutter analysis on small commuter aircraft is still rare. Through this study, it is expected to fill in the gap and to compare with other similar study case which then can be referred to for future aircraft design process. In this work, a specific example of simplification of model for flutter analysis was implemented and was updated gradually throughout the design process. The analysis result from the final adjusted model shows a significant difference with the initial model. The case is focused on the elevator tab model variation of a small commuter aircraft (SCA). Different models were implemented and the effect of aerodynamic hinge variation is also studied to investigate the sensitivity of its flutter characteristic.

\section{Methodology}

The SCA aircraft is a small commuter category with maximum weight of $6,700 \mathrm{~kg}$; powered by dual-engine, installed on a high-wing configuration (see Figure 1a), with aileron and double slotted flaps, equipped with balance tab and trim tab on aileron (see Figure 1d); empennage is using cruciform configuration, with horn on rudder and elevator, equipped with balance tab and trim tab on both rudder (see Figure $1 \mathrm{~b}$ ) and elevator (see Figure 1c). The maximum operating speed (VMO) is 160 Knots $(82.3 \mathrm{~m} / \mathrm{s})$ equivalent air speed (KEAS) and the design dive speed (VD) is $200 \mathrm{KEAS}(102.8$ $\mathrm{m} / \mathrm{s})$. The maximum operational altitude is $12,000 \mathrm{ft}(3657.6 \mathrm{~m})$. The operating envelope is shown on Figure 2.

Trim tab and balance tab are part of trim systems, which have the purpose to help minimize a pilot's workload. Trim systems are attached to the control surface and it works by aerodynamically assist movement and position of its control surface. There are several types of trim systems which are commonly used, such as: trim tabs, balance tabs, balance tabs, anti-servo tabs, ground-adjustable tabs, and an adjustable stabilizer [7].

Trim tabs are the most common installation on aircraft, its purpose is to lighten the stick force for the pilot by maintaining the tab deflection for a certain selected flight configuration (trim condition), thus reducing pilot workload. The trim tab basically will have independent movement with regards to its control surface (tab deflections is independent to its control surface deflections) [14]. Figure 3 illustrates an example of elevator trim tab configuration.

Balance tab is used for the purpose of reducing the control force. Balance tab is similar to trim tab, but it is coupled to the control surface, so that when the pilot moves the control surface, the tab automatically moves in the opposite direction (tab deflections is dependent to its control surface deflections) [14]. Figure 4 illustrates an example of elevator balance tab configuration. 

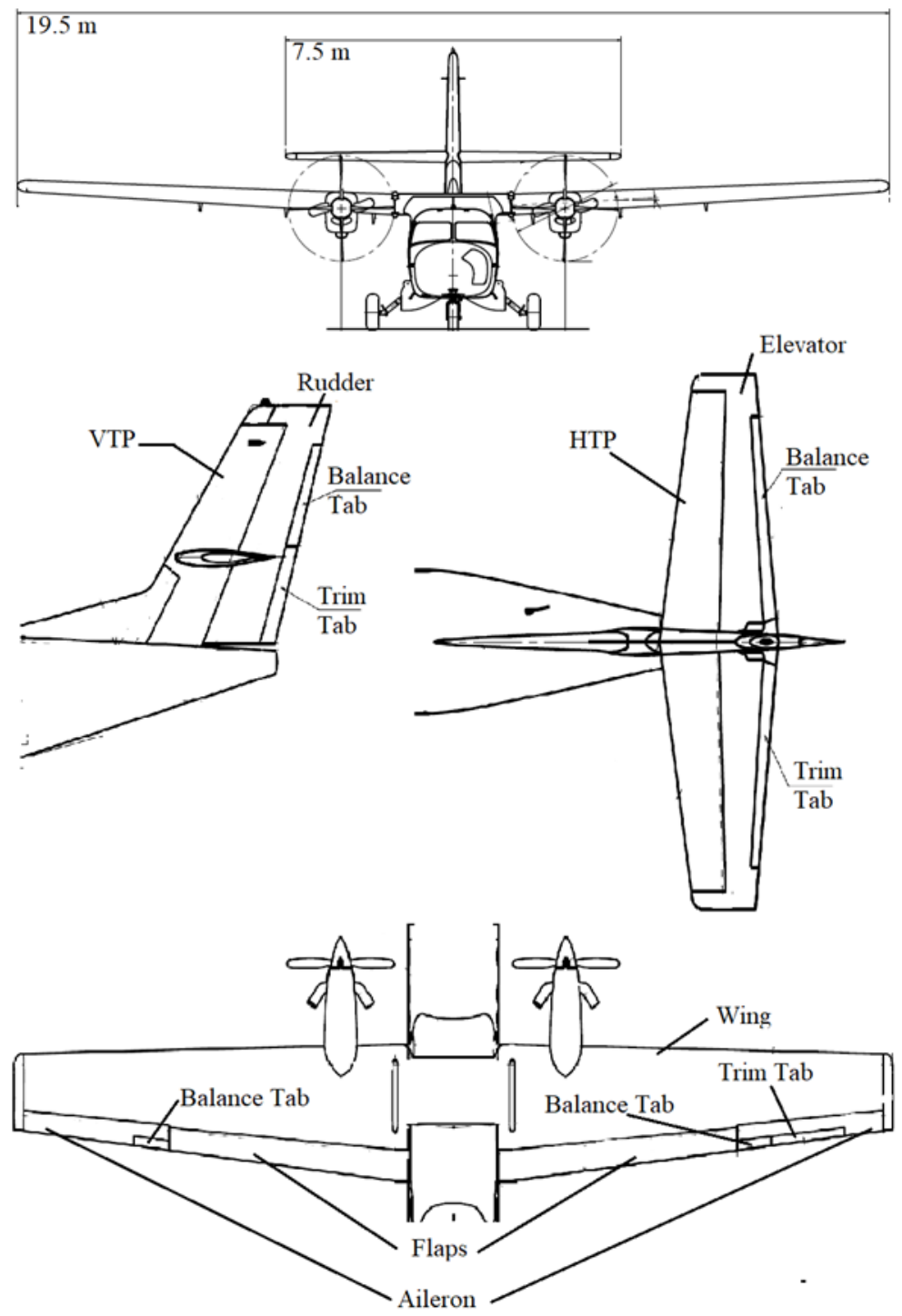

Fig. 1. Configuration Drawing of Small Commuter Aircraft-SCA

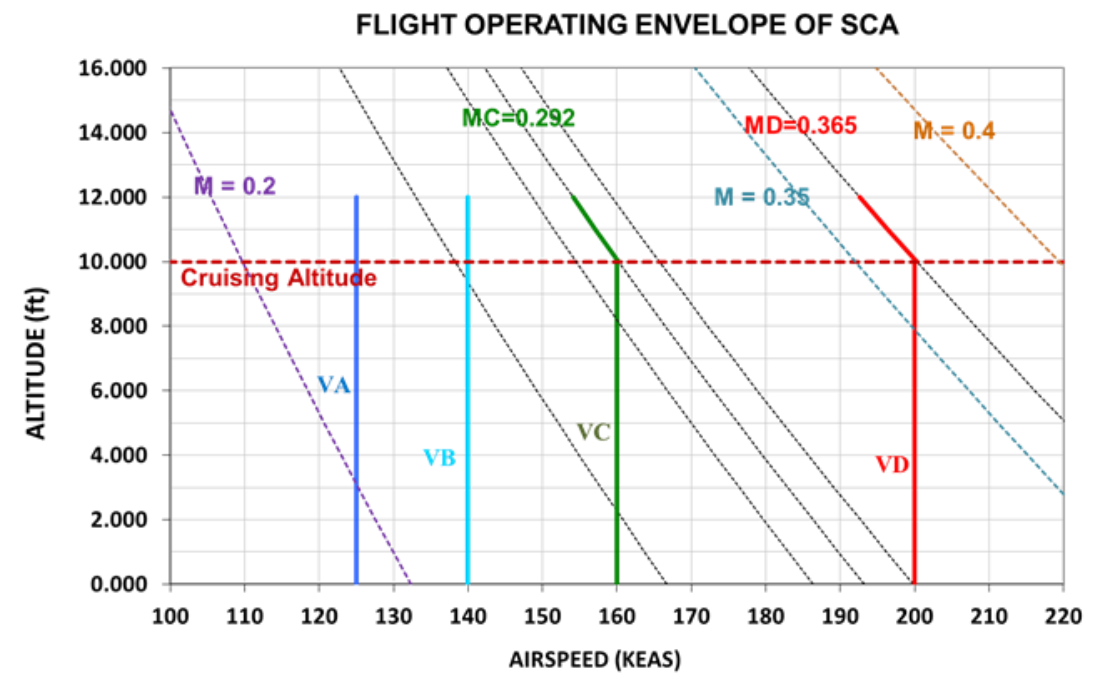

Fig. 2. Flight Operating Envelope of Small Commuter Aircraft (SCA) 


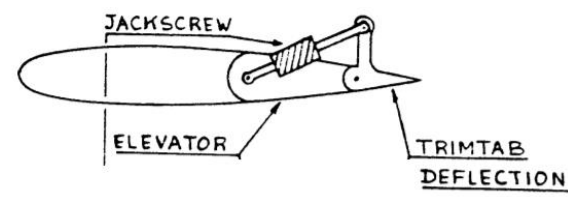

Fig.3. Example of Elevator Trim Tab Configuration [14]

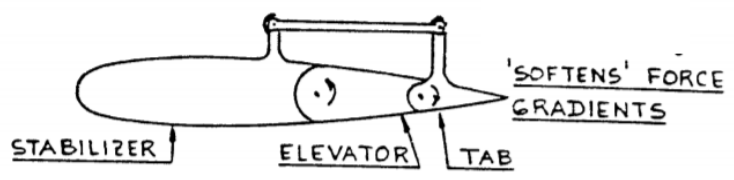

Fig. 4. Example of Elevator Balance Tab Configuration [14]

\subsection{Structure and Aerodynamic Model}

To perform flutter analysis, the aircraft needs to be modelled to represent the structure behavior and aerodynamic behavior, thus there will be structural model and aerodynamic model. The structural model for flutter analysis must be able to represent the structure dynamic (vibration) behavior within the frequency range of interest, therefore the model must be able to give result of natural frequencies, modal masses and normal mode shapes [15].

The aircraft structure will be modelled as beam-like (stick model) which represent the major aircraft components. Performing dynamic and aeroelastic analysis by using stick model is still relevant to be implemented. Research for aero-structure sizing which involve aeroelastic analysis uses stick model to represent the structure [3]. Using stick model for certification process related to aeroelastic analysis is still acceptable by the authority [9].

The beams on stick model are located along the locus of shear center (elastic axis) of the structure. The beam is divided into sections with each member section properties represent the flexural and torsional rigidity of structural component at the section's location (see Figure 5). The mass properties of the components will be represented by concentrated mass which located at the center of gravity of each section and connected to the beam by a rigid connection (see Figure 6$)$. The model should also be able to represent the dynamic of aircraft complexity such as the control surface and its tabs, and the engine installed on the wing. The finite element modelling will be used for analysis on NASTRAN solver.

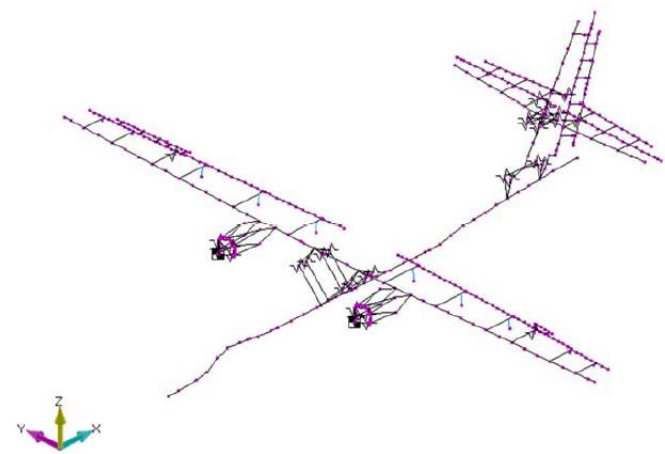

Fig. 5. SCA Aircraft Structure Stick Model

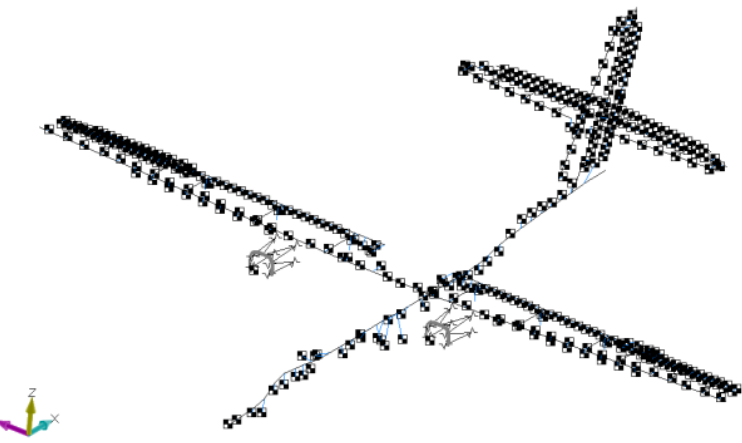

Fig. 6. SCA Aircraft Sectional Concentrated Mass

In this work, the focus will be on the elevator tab model variation and its elevator aerodynamic hinge moment variation. To maintain the focus of evaluation on the effect caused by the elevator tab model variation, thus the aileron and rudder will be locked to its main surface (as consequence: there will be no rudder and aileron rotation modes). Also, the aerodynamic model of the aircraft will not include the aerodynamic model of the wing components (see Figure 7), it will only implement aerodynamic model for empennage (i.e., Vertical Tail Plane and Horizontal Tail Plane), thus focusing only the flutter modes on empennage. Such practice is acceptable for part 23 airplanes (e.g., 
commuter category aircraft) with no unconventional configurations and operational speed below 0.6 Mach. Thus, it is as if the wing and empennage flutter analysis conducted separately [2].

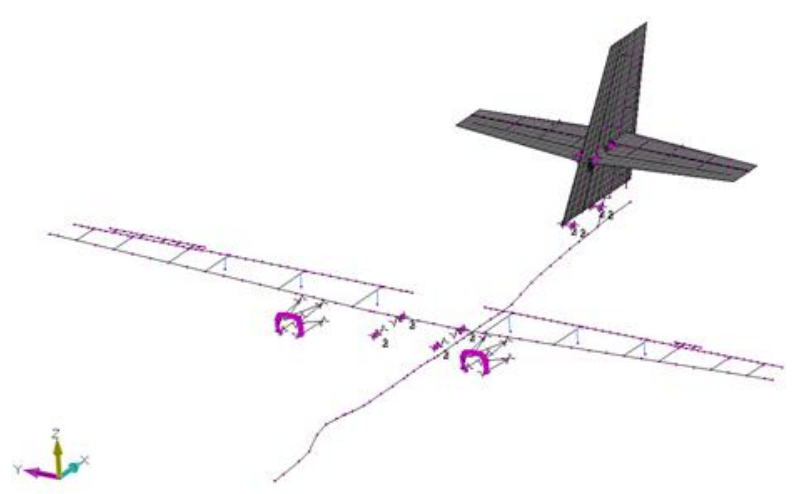

Fig. 7. SCA Aerodynamic Model of Empennage

The structural and aerodynamic model must be connected so that the model will be applicable for flutter analysis. The method for connecting the structural and aerodynamic model is called splining, the spline used in this model is surface spline. The splines are used to build an interpolation between structure and aerodynamic. The independent degrees of freedom are assigned to the structural model, and the dependent degrees of freedom are assigned to the aerodynamic model. The interpolation in spline is basically two transformation process: structural deflections to the aerodynamic deflections; and the interaction between aerodynamic forces with the structural response due to that force [12].

The elevator model tab variation was approached in three steps, the first step was to implement the elevator balance tab and trim tab to be fixed to the elevator (see Figure 8), this means that the rotational modes of both elevator tabs were not available. The second step was to implement the balance tab mechanism into the model with gearing ratio 0.5 (dependent tab movement relative to elevator), and implement independent rotational movement using spring element on the trim tab hinge model (CELAS2), (see Figure 9, Figure 10 and Figure 11).
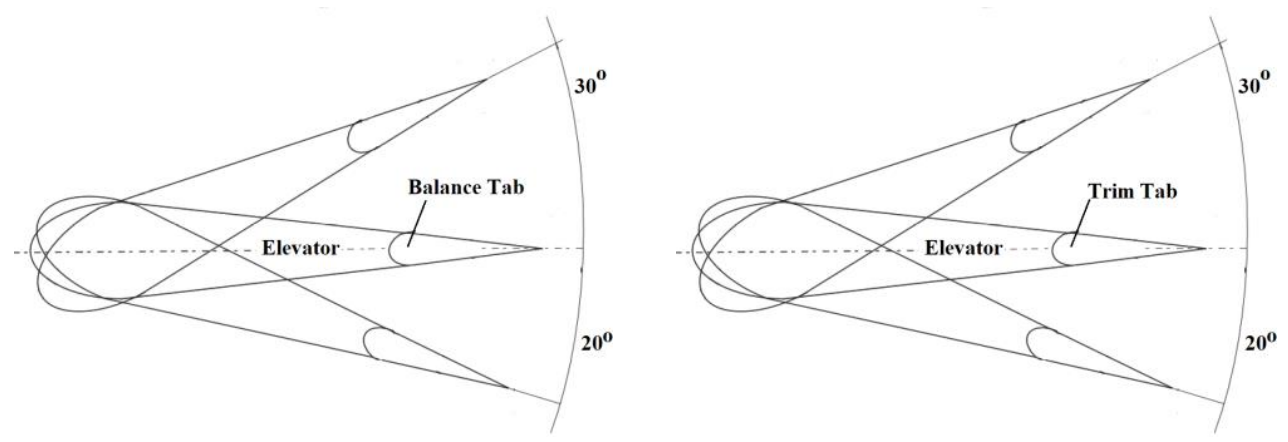

Fig. 8. Elevator Tabs Fixed 

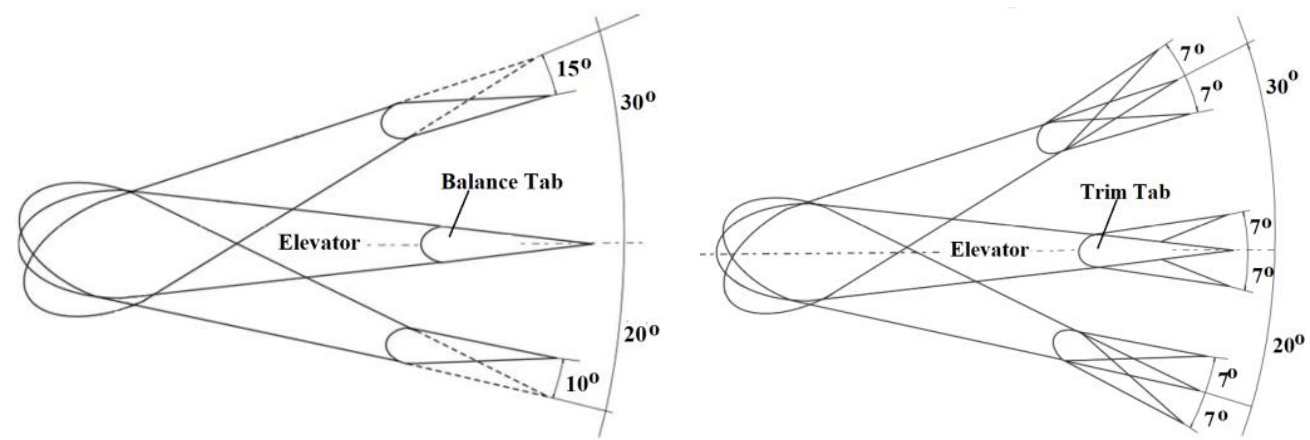

Fig. 9. Elevator Balance Tab dependent movement and Trim tab with independent movement

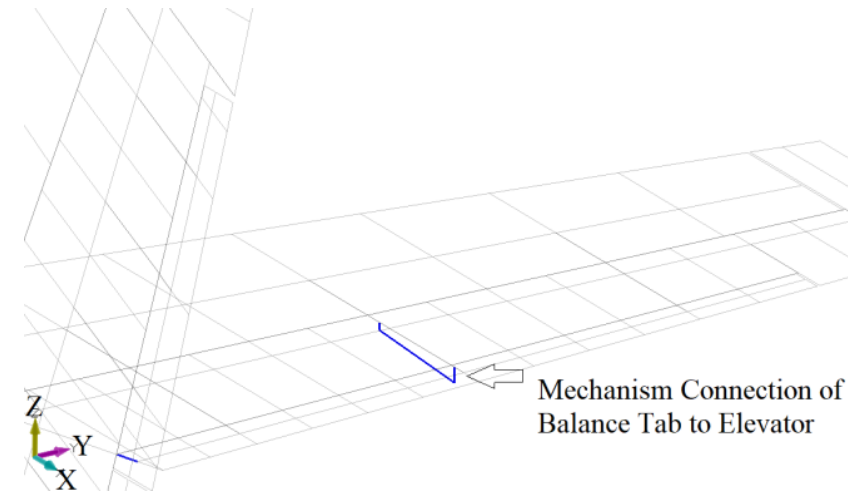

Fig. 10. Mechanism connection of Balance Tab to Elevator

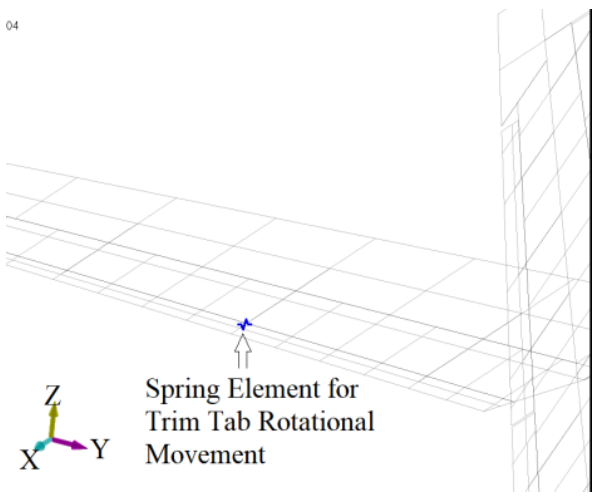

Fig. 11. Spring Element for Trim Tab Rotational Movement

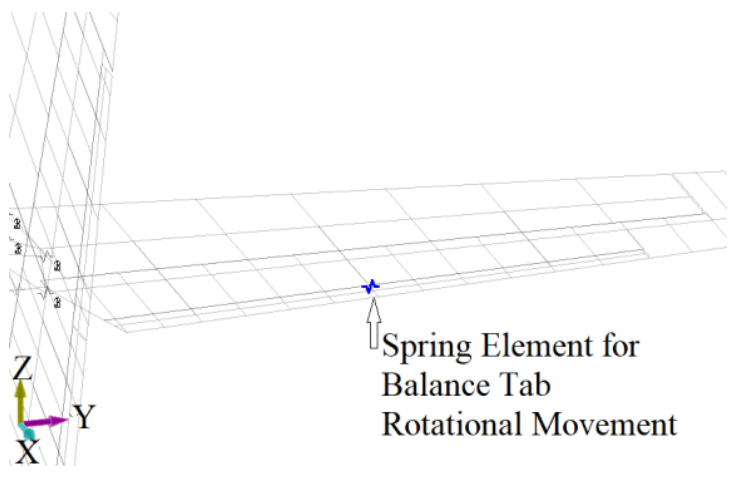

Fig. 12. Spring Element for Balance Tab Rotational Movement

The third variation step was to implement both of the tab (i.e., balance and trim) to use spring element on tab hinge model (see Figure 11 and Figure 12). The spring elements of elevator balance tab and trim tab were optimized to match with the ping test result [9], as shown on Table 1.

\section{Table 1}

Ping Test Result

\begin{tabular}{ll}
\hline & Ping Test Result \\
\hline Control Surface Tab Function & Ping Test Result Frequency (hz) \\
\hline Right Elevator Servo Tab Rotation & 54.0 \\
Left Elevator Tab Rotation & 68.0 \\
\hline
\end{tabular}




\subsection{Normal Modes Analysis Method}

The Normal modes analysis will be performed using NASTRAN SOL103. Normal modes analysis is performed to determine the natural frequencies and mode shapes of structure, it is basically an undamped free vibration (no applied loading) analysis, the basic theory and method for normal modes analysis can be seen on NASTRAN Dynamic Analysis User's Guide [10].

The solution will provide a set of discrete eigenvalues (frequency), and there will be eigenvector (mode shape) which corresponds to each eigenvalue. Each eigenvalue and eigenvector define a free vibration mode of the structure.

The normal modes analysis in this work will be performed for 3 configurations as previously stated in section 2.1. The configuration cases are listed on Table 2 below:

\section{Table 2}

Normal Modes Analysis Case

Normal Modes Analysis Case

\begin{tabular}{ll}
\hline Configuration & Remark \\
\hline Configuration 1 & Fixed Elevator Balance Tab; Fixed Elevator Trim Tab \\
Configuration 2 & $\begin{array}{l}\text { Dependent Mechanism Elevator Balance Tab; } \\
\text { Independent Elevator Trim Tab } \\
\text { Configuration 3 }\end{array}$ \\
& $\begin{array}{l}\text { Independent Elevator Balance Tab; Independent } \\
\text { Elevator Trim Tab }\end{array}$
\end{tabular}

The computation method for Configuration 1 and 3 will be Lanczos, and the Configuration 2 will be using Automatic Householder (AHOU). The frequency range for the analysis is done from 0-75 $\mathrm{Hz}$. The result from ground vibration test has been used as a data input for updating the structural dynamic model. This process serves as a means to validate the numerical model by using the data from test result. The updated model shall be used for normal modes analysis and flutter analysis.

\subsection{Flutter Analysis Method}

The flutter analysis will be performed using NASTRAN SOL145, the method that will be used is PKNL. PKNL is basically the modified PK-method, where it is equivalent to performing a flight test at a constant Mach number while changing the altitude (variable density). It solves the equation considering matched points (consistent values of altitude, Mach and velocity).

The basic equation for PK method in NASTRAN [12] is shown as follow:

$$
\left[M_{h h} p^{2}+\left(B_{h h}-\frac{1}{4} \rho c V Q_{h h}^{I} / k\right) p+\left(K_{h h}-\frac{1}{2} \rho V^{2} Q_{h h}^{R}\right)\right]\left\{u_{h}\right\}
$$

The finite element method will yield all the structural modal matrices $\left(M_{h h}, B_{h h}, K_{h h}\right)$. The aerodynamic lifting surface theory will yield all the aerodynamic modal matrices $\left(Q_{h h}^{R}\right.$ and $\left.Q_{h h}^{I}\right)$ [13]. The real and imaginary terms of $\left[Q_{h h}(m, k)\right]$, which are $\left(Q_{h h}^{R}\right.$ and $\left.Q_{h h}^{I}\right)$ respectively, and these are a function of Mach number $(\mathrm{m})$ and reduced frequency $(\mathrm{k})$. Furthermore, the relation of $\mathrm{k}$ and $\mathrm{m}$ are not independent and can be expressed as:

$$
k=(c / 2 V) \operatorname{lm}(p)
$$


Doublet-lattice method of Giesing, Kalman, and Rodden [12]Error! Reference source not found. is the aerodynamic lifting surface theory used for analysis in subsonic flow. The result from Doubletlattice method, $\left[Q_{h h}\right]$, is where the spline function is applied and transformed into generalized form. The Eq. (Error! Reference source not found. needs to be rewritten into state-space matrix form for solutions in NASTRAN, as follow:

$$
\begin{aligned}
& {[A-p I]\left\{u_{h}\right\}=0} \\
& {[A]=\left[\frac{0}{-M_{h h}^{-1}\left[K_{h h}-\frac{1}{2} \rho V^{2} Q_{h h}^{R}\right]} \mid \frac{I}{-M_{h h}^{-1}\left[B_{h h}-\frac{1}{4} \rho c V Q_{h h}^{I} / k\right]}\right]}
\end{aligned}
$$

where $[A]$ is the real matrix and $\left\{u_{h}\right\}$ now includes both modal displacements and velocities [12].

The eigenvalue and eigenvector solution of Eq. ( 3 are calculated in NASTRAN using the upper Hessenberg method described by Komzsik [8]. The solution of the real matrix [A] in eigenvalues will give either real or complex conjugate pairs. Real roots eigenvalue is categorized as solution for divergence. Meanwhile, the complex conjugate pairs eigenvalue commonly will dominate the results from matrix $[A]$, is the solution for flutter. "The oscillatory solutions of Eq. (1) require an iterative solution so that Eq. (2) is satisfied along with Eq. (1) [12].

The result for flutter solution is shown in $\mathrm{Vg}-\mathrm{Vf}$ diagram as shown on example diagram below (Figure 13), the Vg plot shows the damping (g) as a function to airspeed (V), whilst the Vf plot shows the frequency ( $f$ ) as a function to airspeed. The flutter speed is determined as the critical speed when the damping goes from stable region (negative value) into unstable region (positive value). There is general practice which applies that damping value of $g=+0.03$ as the inherent structural damping can be used to determine the critical speed as the flutter speed [2]. Thus, from Vg plot example below it can be seen that the flutter only occurs on the mode with light-blue line, and the critical speed occurs when the damping passes the damping value of 0.03 , which is approximately around $290 \mathrm{KEAS}$. The $V f$ plot can be used to evaluate the shifting of frequency behavior for the flutter modes. Aside from that, $\mathrm{Vf}$ can also be used to determine whether the occurred phenomenon is flutter or divergence. On divergence case, near to the critical speed, the frequency will become zero.

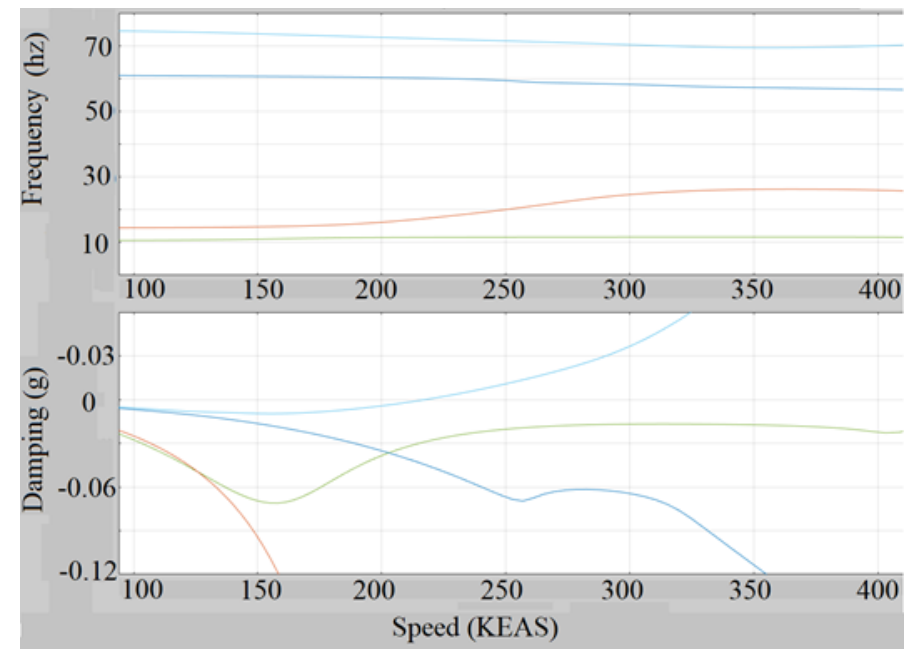

Fig. 13. Vg-Vf diagram 
The SCA aircraft is categorized based on CASR Part 23 (Civil Aviation Safety Regulation) which stated on chapter $\mathbf{2 3 . 6 2 9}$ for flutter, that "any rational analysis used to predict freedom from flutter, control reversal and divergence must cover all speeds up to $1.2 \mathrm{~V}_{\mathrm{D}} / 1.2 \mathrm{MD}$, limited to Mach 1.0 for subsonic airplanes [1].

For this work, there will be three configurations on flutter analysis, as previously explained in section 2.1, the configurations list is shown on Table 3 below.

\section{Table 3}

Flutter Analysis Configurations Case List

\begin{tabular}{llll}
\hline \multicolumn{2}{l}{ Flutter Analysis Study Case } & & \\
\hline Configuration & Remark & Nominal Case & Parametric Case \\
\hline $\begin{array}{l}\text { Configuration } \\
1\end{array}$ & Fixed Elevator Balance Tab; & Mach Variation: 0.1, 0.2, & Elevator Aerodynamic Hinge \\
& Fixed Elevator Trim Tab & $\begin{array}{l}0.3,0.4,0.5 \text { (finding } \\
\text { most critical) }\end{array}$ & $\begin{array}{l}\text { Moment Variaton: 70\%, 85\%, 100\% } \\
\text { (nominal), 115\%, 130\% }\end{array}$ \\
$\begin{array}{llll}\text { Configuration } \\
2\end{array}$ & Dependent Mechanism Elevator & Nominal Case (most & Elevator Aerodynamic Hinge \\
& Balance Tab; Independent & critical) & Moment Variaton: 70\%, 85\%, 100\% \\
Configuration & Elevator Trim Tab & & (nominal), 115\%, 130\% \\
3 & Independent Elevator Balance & Nominal case (most & Elevator Aerodynamic Hinge \\
& Tab; Independent Elevator Trim & critical) & Moment Variaton: 70\%, 85\%, 100\% \\
& Tab & & (nominal), 115\%, 130\% \\
\hline
\end{tabular}

\section{Results and Discussion}

\subsection{Normal Modes Analysis Result}

The results from normal modes analysis are pairs of frequency and mode shape. The results of normal modes analysis for each configuration will be provided in this section. The results that are shown here are only for the related mode shape from the flutter analysis results.

- Configuration 1:

○ Mode 17: $10.28 \mathrm{~Hz}$

Elevator Rotation (Anti-Symmetric) shown on Figure 14.

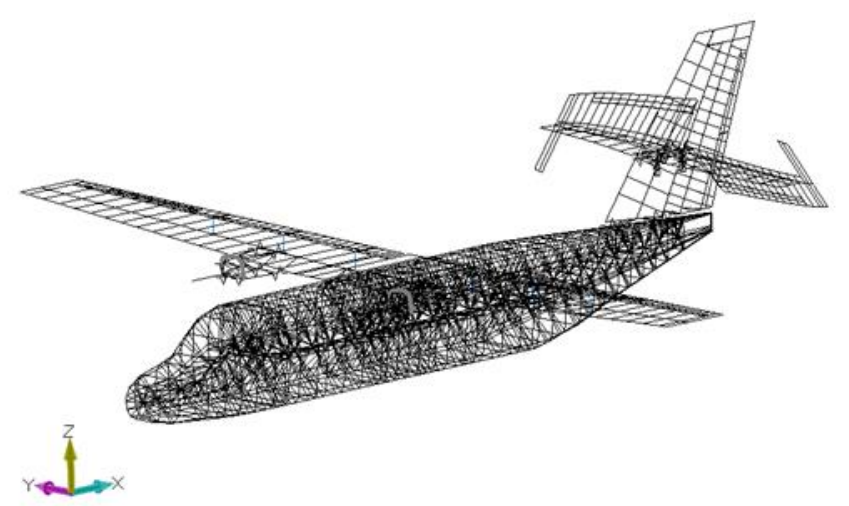

Fig. 14. Mode 17, Result from Configuration 1

- Configuration 2:

○ Mode 73: $69.64 \mathrm{~Hz}$

Elevator Horn Bending, Elevator Balance Tab Torsion, Rudder Torsion (AntiSymmetric) shown on Figure 15.

o Mode 17: $10.3 \mathrm{~Hz}$ 


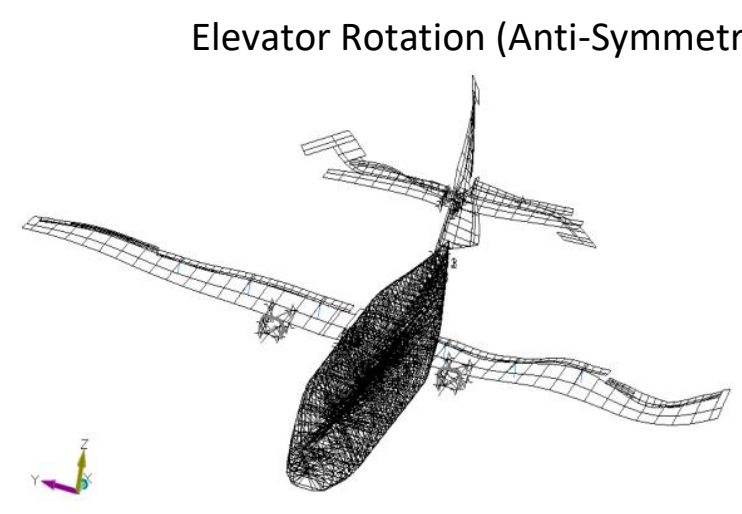

Fig. 15. Mode 73, Result from Configuration 2

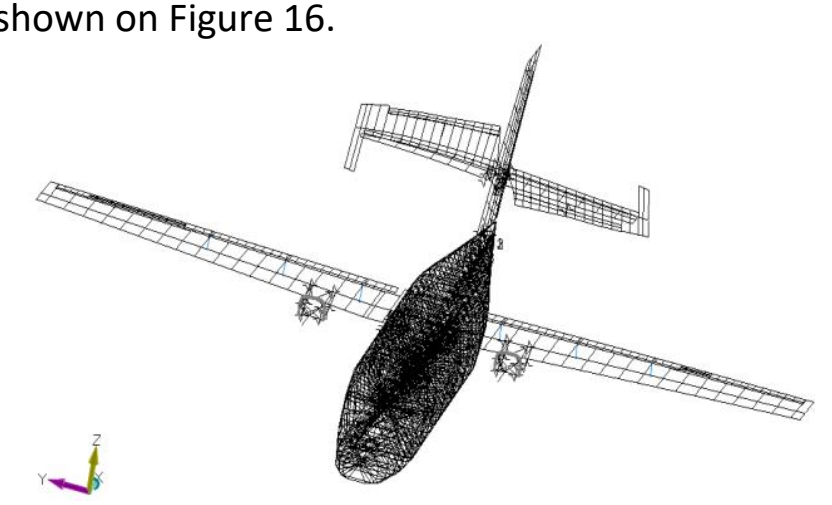

Fig.16. Mode 17, Result from Configuration 2

- Configuration 3:

○ Mode $76: 74.85 \mathrm{~Hz}$

HTP Torsion, Elevator Balance \& Trim Tab Torsion and Rotation (Anti-Symmetric) shown on Figure 17.

- Mode 67: $67.34 \mathrm{~Hz}$

Elevator Horn Bending, Elevator Balance \& Trim Tab Rotation (Symmetric) shown on Figure 18.

○ Mode 17: $10.25 \mathrm{~Hz}$

Elevator Rotation (Anti-Symmetric) shown on Figure 19.

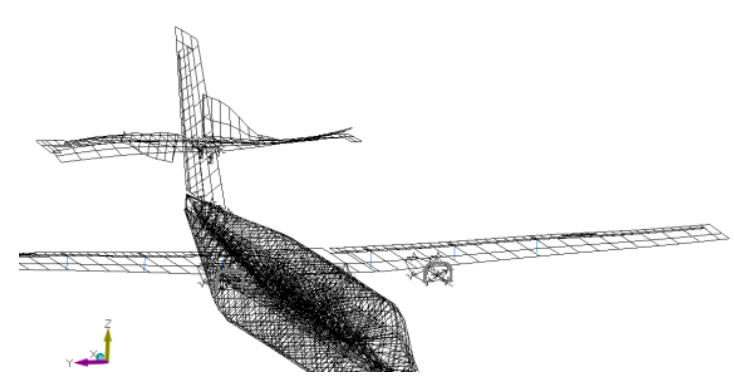

Fig. 17. Mode 76, Result from Configuration 3

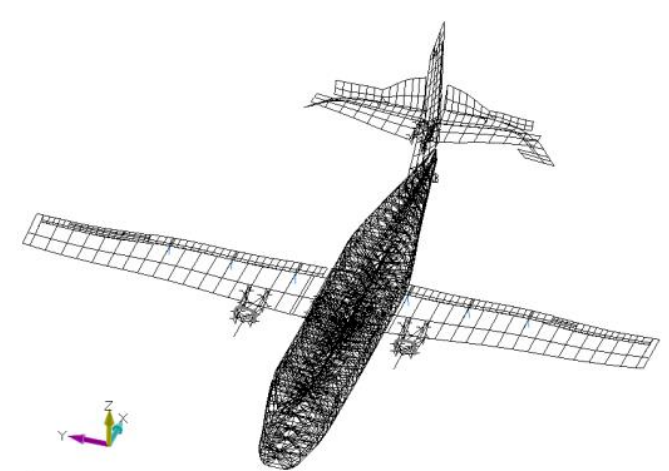

Fig. 18. Mode 67, Result from Configuration 3

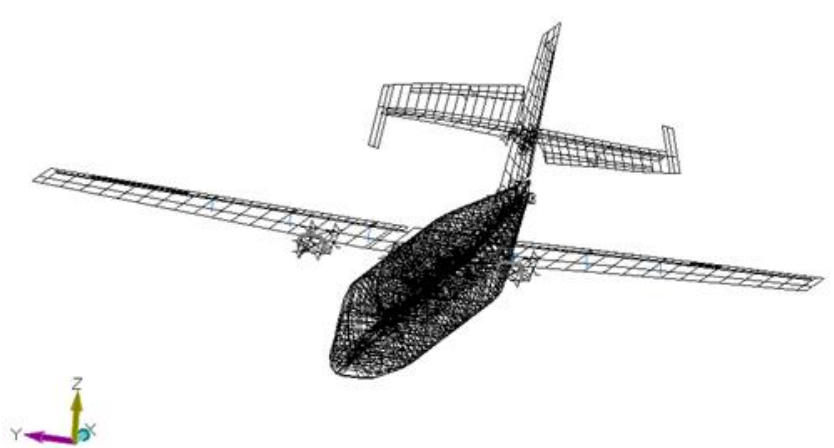

Fig. 19. Mode 17, Result from Configuration 3 


\subsection{Flutter Analysis Result}

- Configuration 1

The flutter analysis result on configuration 1 for nominal case with Mach number variation shows that flutter only occurs from Mach 0.3 to Mach 0.5 (see Table 4). The most critical flutter occurs at Mach 0.3; thus, the following analyses will be done on the most critical condition, Mach 0.3. The flutter speed for the most critical condition is 401.52 KEAS on mode 17: $10.22 \mathrm{~Hz}$, Elevator rotation (anti-symmetric). Figure 20 shows the flutter envelope based on the flutter analysis result, it can be seen that all the flutter occurs outside the envelope, beyond 1.2 VD (240 KEAS). The altitude for each flutter results is matched with the Mach number and speed (matched-point solution), the analysis on negative altitude was done to provide the result for illustration in the envelope. The $\mathrm{Vg}$ - Vf diagram is shown on Figure 21 for result at Mach number 0.3.

\section{Table 4}

Flutter Analysis Result for Configuration 1 (NominalMach Variation)

\begin{tabular}{lll}
\hline \multicolumn{3}{l}{ Flutter Analysis Result Configuration-1 } \\
\hline Mach No. & Mode 17 \\
\cline { 2 - 3 } & Flutter Speed (KEAS) & Flutter Freq. (Hz.) \\
\hline 0.3 & 401.52 & 10.22 \\
0.4 & 449.58 & 10.19 \\
0.5 & 492.04 & 10.16 \\
\hline
\end{tabular}

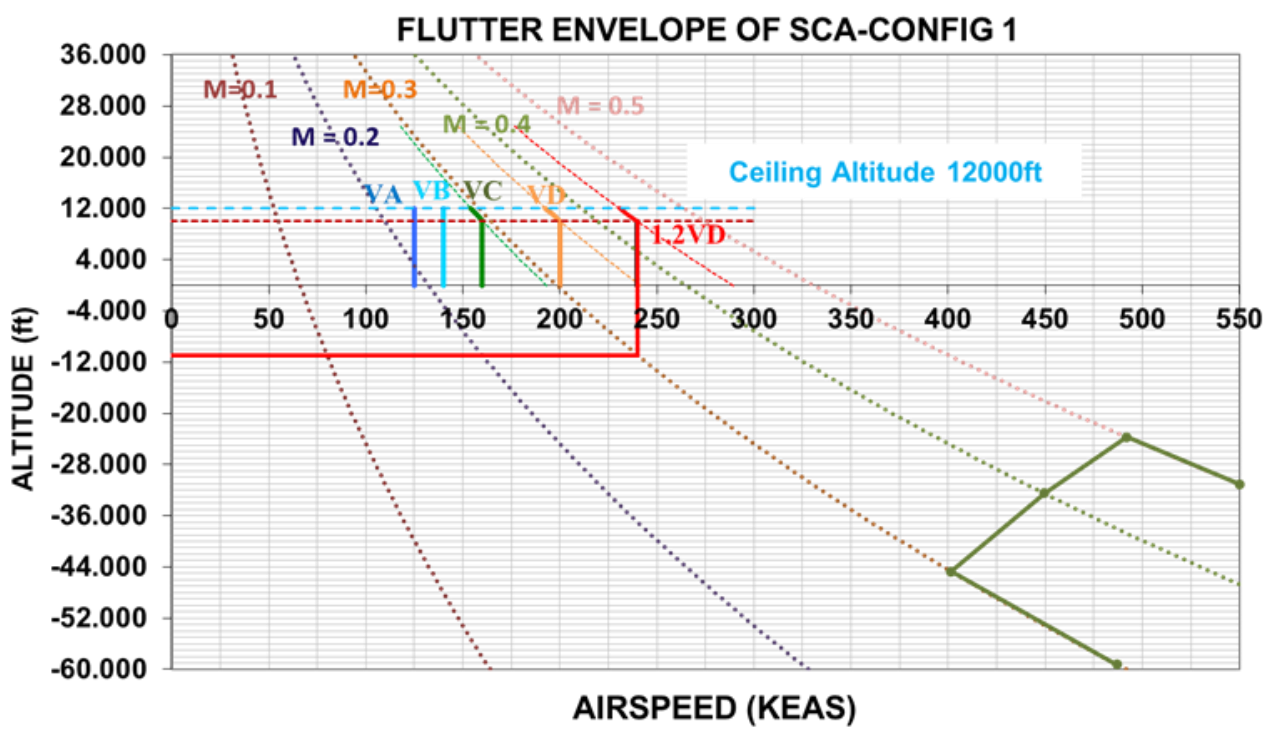

Fig. 20. Flutter Envelop for Configuration 1 


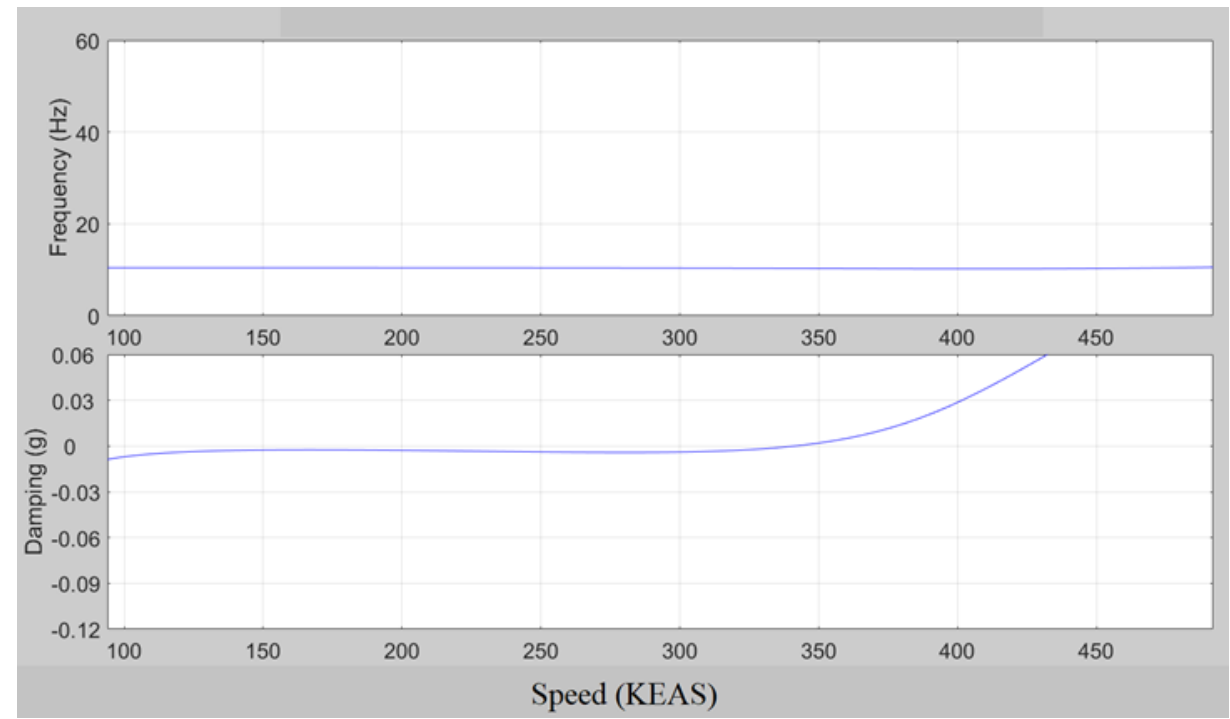

Fig. 21. $\mathrm{Vg}$-Vf diagram for Nominal Configuration-1 $(\mathrm{M}=0.3)$

The parametric analysis for elevator aerodynamic hinge moment variation shows that for configuration 1, there are no significant effect to the flutter characteristic (see Table 5 and Figure 22).

Table 5

Flutter Parametric Result for Configuration-1

\begin{tabular}{lll}
\hline \multicolumn{3}{l}{ Flutter Parametric Result Configuration-1 } \\
\hline $\begin{array}{l}\text { Elevator Aero } \\
\text { Var. (\%) }\end{array}$ & $\begin{array}{l}\text { Mode 17 } \\
\text { (KEAS) }\end{array}$ & \\
\hline 70 & 401.44 & Flutter Freq. (Hz.) \\
85 & 401.54 & 10.22 \\
100 & 401.52 & 10.22 \\
115 & 401.4 & 10.22 \\
130 & 401.24 & 10.21 \\
\hline
\end{tabular}

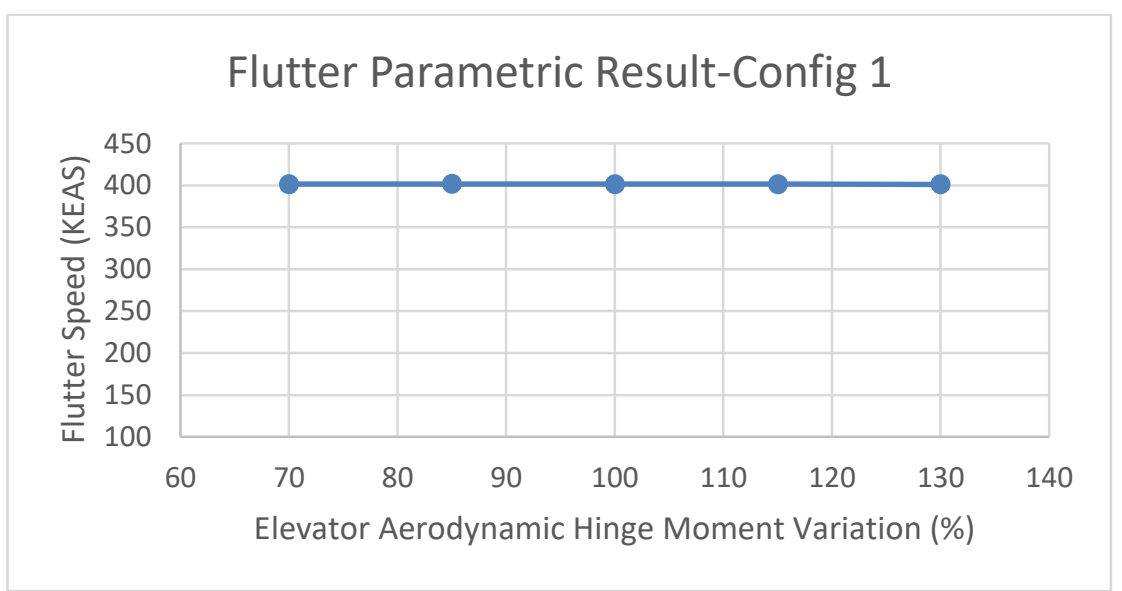

Fig. 22. Flutter Parametric Result for Configuration 1

- Configuration 2

The flutter analysis result on configuration 2 for nominal condition shows that the most critical flutter occurs at speed 368.53 KEAS (see Table 6) on mode 73: $68.21 \mathrm{~Hz}$, Elevator Horn 
Bending, Elevator Balance Tab Torsion, Rudder Torsion (Anti-Symmetric). The Vg-Vf diagram is shown on Figure 23 for result at Mach number 0.3.

Table 6

Flutter Analysis Nominal Result for Configuration 2

\begin{tabular}{lllll}
\hline \multicolumn{5}{l}{ Flutter Analysis Result Configuration-2 } \\
\hline Mach No. & Mode 73 & & Mode 17 \\
\cline { 2 - 5 } & $\begin{array}{l}\text { Flutter Speed } \\
\text { (KEAS) }\end{array}$ & $\begin{array}{l}\text { Flutter Freq. } \\
(\mathrm{Hz} .)\end{array}$ & $\begin{array}{l}\text { Flutter Speed } \\
\text { (KEAS) }\end{array}$ & $\begin{array}{l}\text { Flutter Freq. } \\
\text { (Hz.) }\end{array}$ \\
\hline 0.3 & 368.53 & 68.21 & 395.66 & 10.23 \\
\hline
\end{tabular}

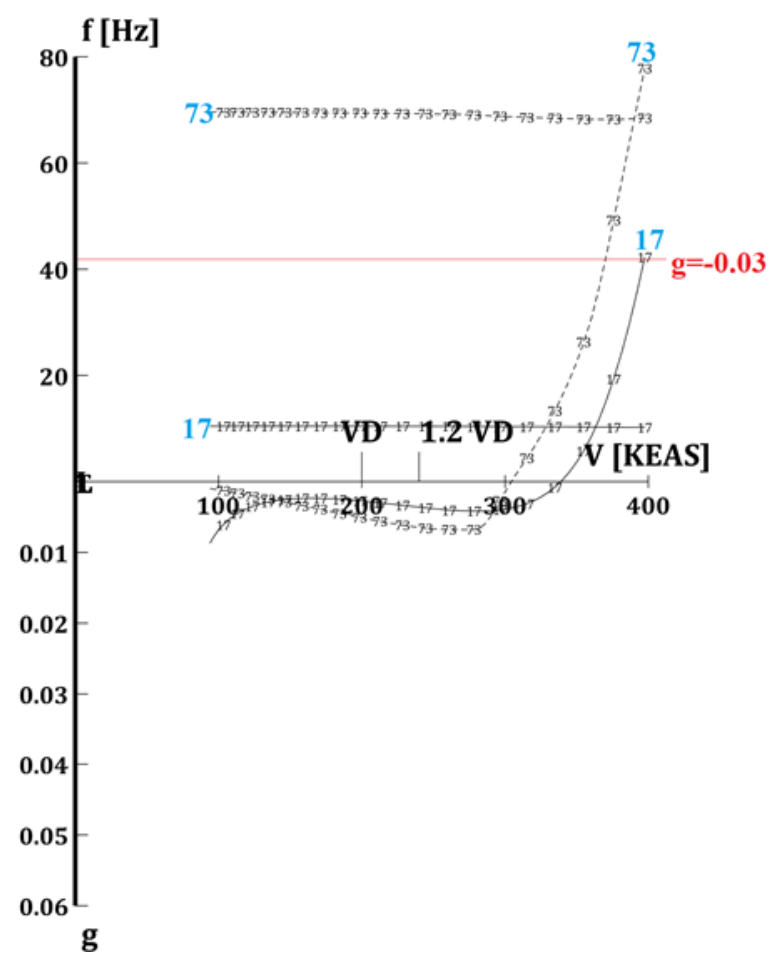

Fig. 23. Vg-Vf Diagram for Nominal Configuration 2

The flutter parametric result of elevator hinge moment variation for configuration 2 can be seen in Table 7 and Figure 24. It can be seen that the elevator aerodynamic hinge moment variation on configuration 2 does not give significant effect to the flutter speed.

\section{Table 7}

Flutter Parametric Result for Configuration-2

\begin{tabular}{|c|c|c|c|c|c|c|}
\hline \multicolumn{7}{|c|}{ Flutter Parametric Result Configuration-2 } \\
\hline \multirow{2}{*}{$\begin{array}{l}\text { Elevator Aero } \\
\text { Var. (\%) }\end{array}$} & \multicolumn{2}{|c|}{ Mode 17} & \multicolumn{2}{|c|}{ Mode 68} & \multicolumn{2}{|c|}{ Mode 73} \\
\hline & $\begin{array}{l}\text { Flutter } \\
\text { Speed } \\
\text { (KEAS) }\end{array}$ & $\begin{array}{l}\text { Flutter } \\
\text { Freq. } \\
\text { (Hz.) }\end{array}$ & $\begin{array}{l}\text { Flutter } \\
\text { Speed } \\
\text { (KEAS) }\end{array}$ & $\begin{array}{l}\text { Flutter } \\
\text { Freq. } \\
\text { (Hz.) }\end{array}$ & $\begin{array}{l}\text { Flutter } \\
\text { Speed } \\
\text { (KEAS) }\end{array}$ & $\begin{array}{l}\text { Flutter } \\
\text { Freq. } \\
(\mathrm{Hz} .)\end{array}$ \\
\hline 70 & 396.61 & 10.23 & 370.09 & 66.82 & - & - \\
\hline 85 & 396.17 & 10.23 & - & - & 374.56 & 67.62 \\
\hline 100 & 395.66 & 10.23 & - & - & 368.53 & 68.21 \\
\hline 115 & 395.1 & 10.23 & - & - & 367.8 & 68.63 \\
\hline 130 & 394.5 & 10.23 & - & - & 373.36 & 69.14 \\
\hline
\end{tabular}




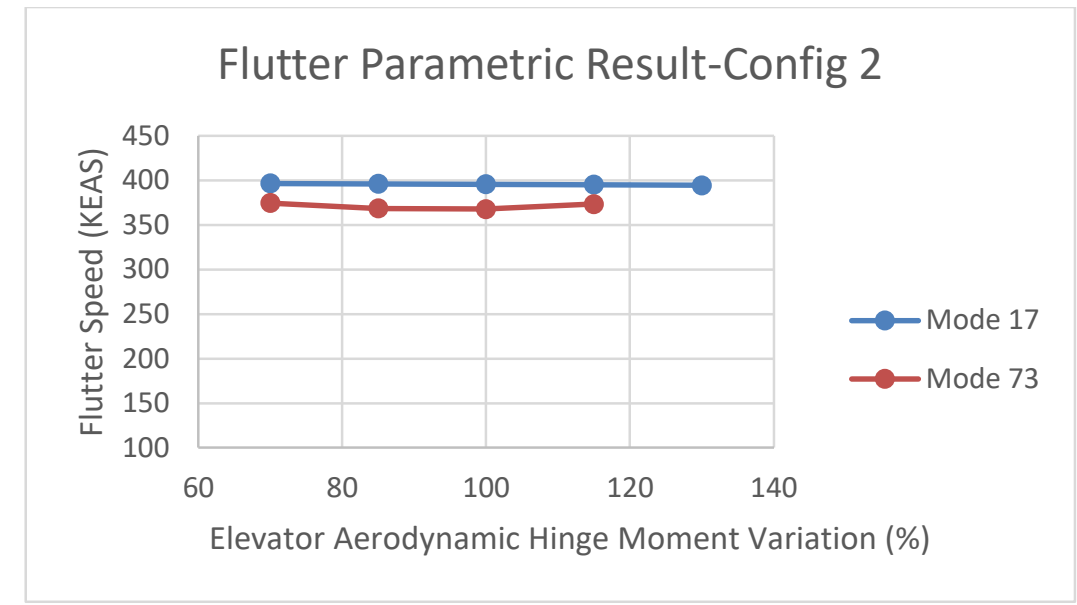

Fig. 24. Flutter Parametric Result for Configuration 2

- Configuration 3

The flutter analysis result on configuration 3 for nominal condition shows that the most critical flutter occurs at speed 290.42 KEAS (see Table 8) on mode 76: $70.54 \mathrm{~Hz}$, HTP Torsion, Elevator Balance \& Trim Tab Torsion and Rotation (Anti-Symmetric). The Vg-Vf diagram is shown on Figure 25 for result at Mach number 0.3.

\section{Table 8}

Flutter Analysis Nominal Result for Configuration 3

\begin{tabular}{|c|c|c|c|c|c|c|}
\hline \multicolumn{7}{|c|}{ Flutter Analysis Result Configuration-3 } \\
\hline \multirow[t]{3}{*}{ Mach No. } & \multicolumn{2}{|c|}{ Mode 76} & \multicolumn{2}{|c|}{ Mode 67} & \multicolumn{2}{|c|}{ Mode 17} \\
\hline & Flutter & Flutter & Flutter & Flutter & Flutter & Flutter \\
\hline & $\begin{array}{l}\text { Speed } \\
\text { (KEAS) }\end{array}$ & Freq. (Hz.) & $\begin{array}{l}\text { Speed } \\
\text { (KEAS) }\end{array}$ & Freq. (Hz.) & $\begin{array}{l}\text { Speed } \\
\text { (KEAS) }\end{array}$ & Freq. (Hz.) \\
\hline 0.3 & 290.42 & 70.54 & 330.86 & 66.45 & 395.51 & 10.23 \\
\hline
\end{tabular}

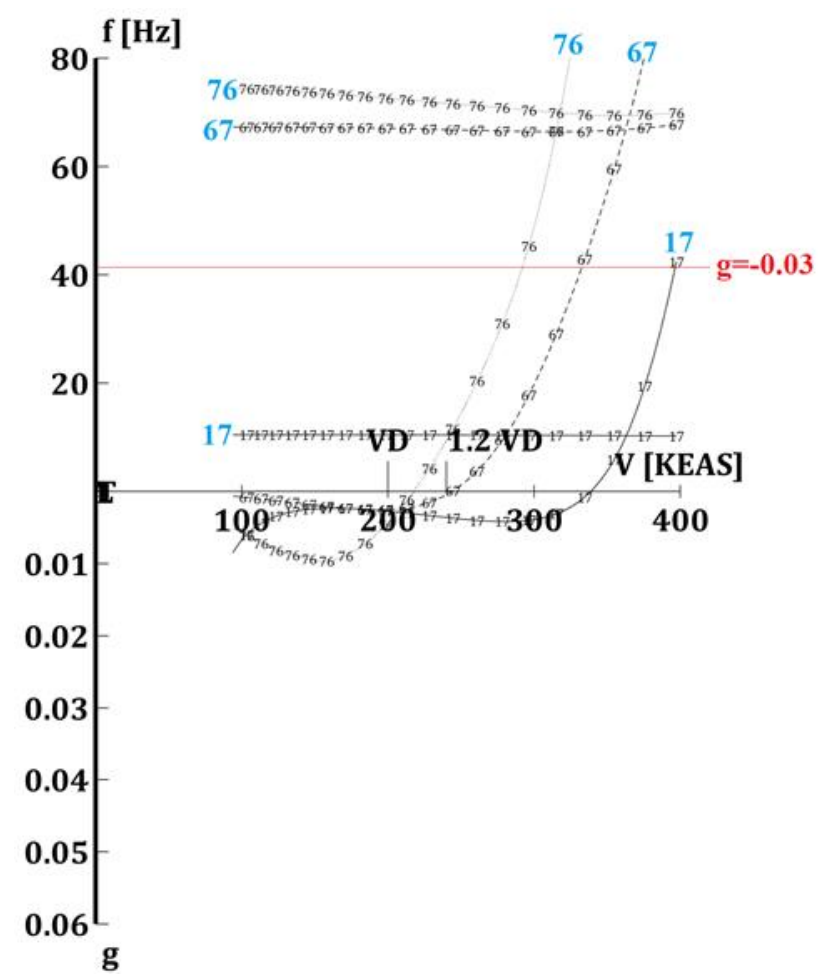

Fig, 25. Vg-Vf Diagram for Nominal Configuration 3 
The flutter parametric result of elevator hinge moment variation for configuration 3 can be seen in Table 9 and Figure 26. It can be seen that there is significant decrease in flutter speed for mode 76: HTP Torsion, Elevator Balance \& Trim Tab Torsion and Rotation (Anti-Symmetric), the flutter speed decrease as the aerodynamic hinge moment contribution increases.

\section{Table 9}

Flutter Parametric Result for Configuration-3

\begin{tabular}{|c|c|c|c|c|c|c|}
\hline \multicolumn{7}{|c|}{ Flutter Parametric Result Configuration-3 } \\
\hline \multirow[t]{2}{*}{ Elevator Aero Var. (\%) } & \multicolumn{2}{|c|}{ Mode 17} & \multicolumn{2}{|c|}{ Mode 67} & \multicolumn{2}{|c|}{ Mode 76} \\
\hline & $\begin{array}{l}\text { Flutter } \\
\text { Speed } \\
\text { (KEAS) }\end{array}$ & $\begin{array}{l}\text { Flutter Freq. } \\
(\mathrm{Hz} .)\end{array}$ & $\begin{array}{l}\text { Flutter } \\
\text { Speed } \\
\text { (KEAS) }\end{array}$ & $\begin{array}{l}\text { Flutter Freq. } \\
(\mathrm{Hz} .)\end{array}$ & $\begin{array}{l}\text { Flutter } \\
\text { Speed } \\
\text { (KEAS) }\end{array}$ & $\begin{array}{l}\text { Flutter Freq. } \\
(\mathrm{Hz} .)\end{array}$ \\
\hline 70 & 396.77 & 10.23 & 334.93 & 66.16 & 316.23 & 70.2 \\
\hline 85 & 396.17 & 10.23 & 331.36 & 66.3 & 301.74 & 70.41 \\
\hline 100 & 395.51 & 10.23 & 330.86 & 66.45 & 290.42 & 70.54 \\
\hline 115 & 394.81 & 10.23 & 334.77 & 66.65 & 281.31 & 70.64 \\
\hline 130 & 394.09 & 10.23 & - & - & 273.82 & 70.71 \\
\hline
\end{tabular}

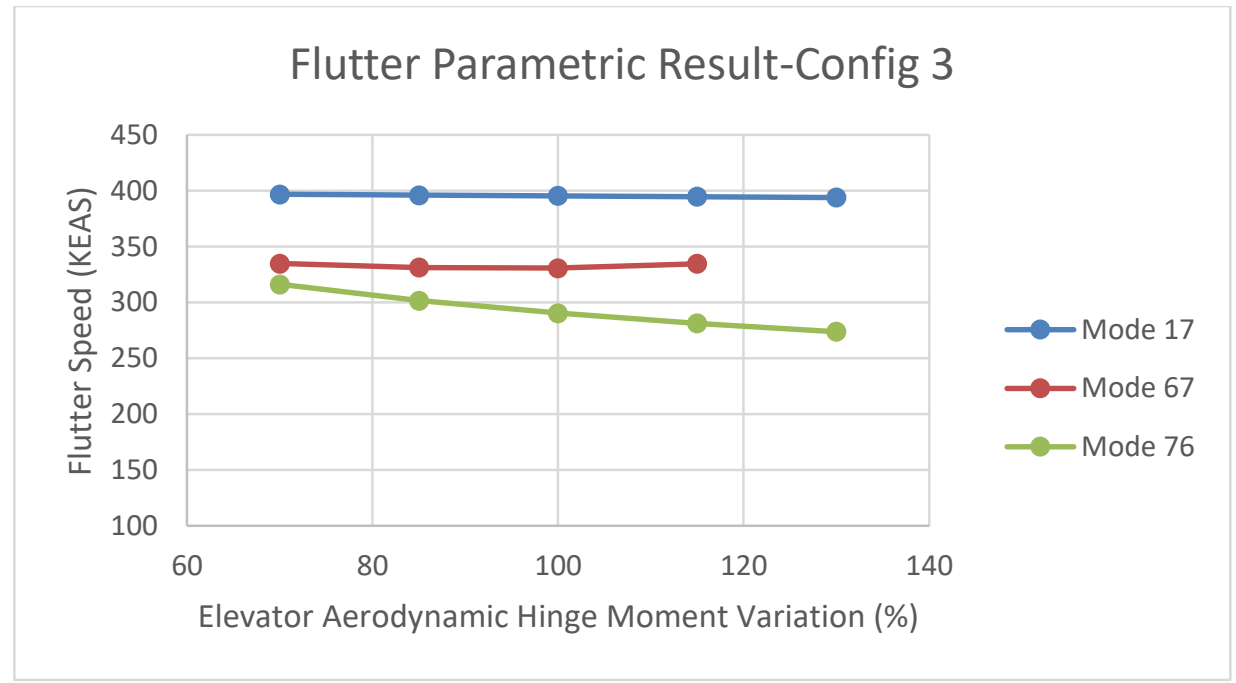

Fig. 26. Flutter Parametric Result for Configuration 3

\subsection{Discussion}

Based on the flutter analysis result, the effect of the modification in the elevator tab model can be compared, the comparison is shown on Table 10 and Figure 27. The comparison shows that configuration 3 (the newest configuration) have the most critical flutter speed. Even though the flutter speed is still safe (i.e., more than $1.2 \mathrm{VD}$ ) with reference to the regulation [1], but the significant decrease of flutter speed cannot be ignored from a design process perspective.

In the early design process, because the result of the analysis will not be directly used in the certification process, thus it was decided to use a simpler tab model (i.e., configuration 1). But, by looking at the effect of the tab onto the flutter speed are more severe throughout the model development, it is better for the tab to be modelled from the early design process. Thus, if any critical flutter appears and needs to be responded by a change in design (e.g., tab mass balance, tab mechanical/hydraulic system modification, etc), it can be implemented earlier, and avoid any costly risk if it was implemented on later design phase.

More efforts need to be attended towards a proper tab modelling, several recommendations related to the importance in modelling, parametric analysis, and validation testing are available in $A C$ 
23.629-1B [2]. These recommendations are already known, but the method to implement this on early design phase without causing significant delay and cost to the design process must be explored.

Table 10

Most Critical Flutter Speed Comparison

\begin{tabular}{llll}
\hline Most Critical Flutter Speed & & \\
\hline Configuration & $\begin{array}{l}\text { Flutter Speed } \\
\text { (KEAS) }\end{array}$ & $\begin{array}{l}\text { Flutter Freq. } \\
(\mathrm{Hz} .)\end{array}$ & Flutter Mode \\
\hline Configuration 1 & 401.52 & 10.22 & 17 \\
Configuration 2 & 368.27 & 69.6 & 73 \\
Configuration 3 & 290.42 & 70.54 & 76 \\
\hline
\end{tabular}

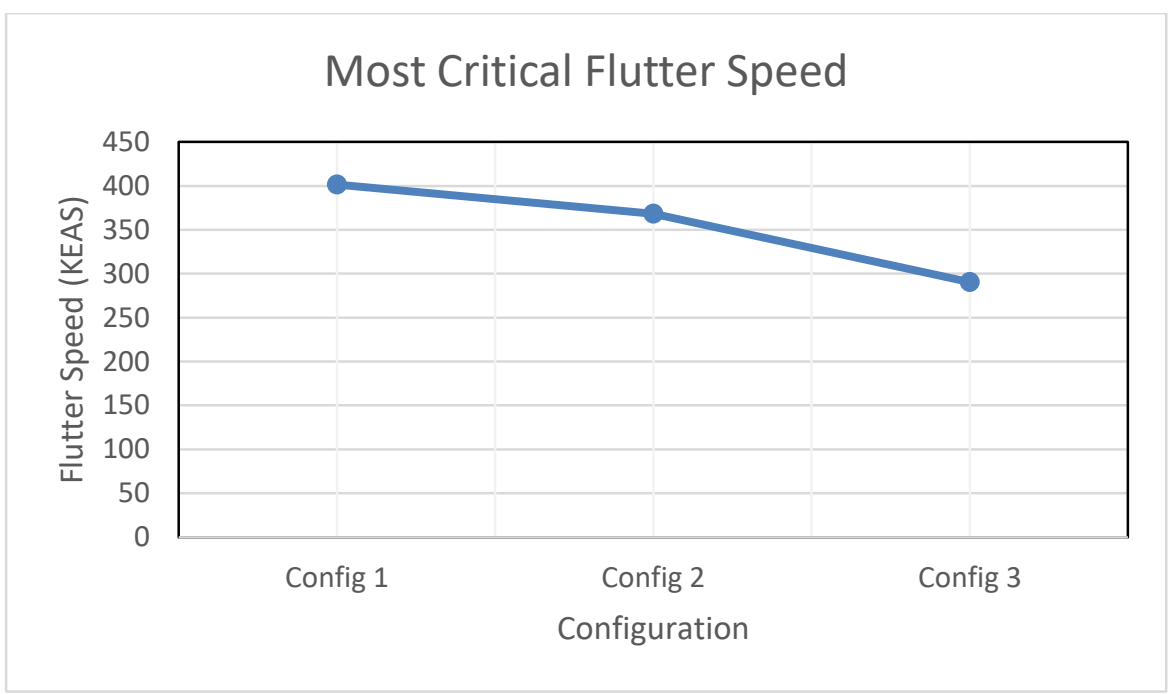

Fig. 27. Most Critical Flutter Speed Trend

The parametric evaluation for elevator aerodynamic hinge moment variation (Figure 22, Figure 24 and Figure 26) shows that the significant effect only appears in configuration 3 . Based on the comparison in Table 11 and the result from parametric evaluation, it seems that the aerodynamic variation takes effect when the mode involves both of the tab rotation and tab elastic modes (e.g., tab torsion). In configuration 3, mode 67 involves both of the tab, but does not have tab elastic modes, and from Figure 25 we can see that the parametric variation does not give significant effect to the flutter speed.

Table 11

Flutter Mode Comparison

\begin{tabular}{|c|c|c|}
\hline \multicolumn{3}{|c|}{ Flutter Mode Comparison } \\
\hline Configuration & Mode Shape & Flutter Mode \\
\hline Configuration 1 & Elevator Rotation (Anti-Symmetric) & Mode 17 \\
\hline \multirow[t]{2}{*}{ Configuration 2} & $\begin{array}{l}\text { Elevator Horn Bending, Elevator Balance Tab } \\
\text { Torsion, Rudder Torsion (Anti-Symmetric) }\end{array}$ & Mode 73 \\
\hline & Elevator Rotation (Anti-Symmetric) & Mode 17 \\
\hline \multirow[t]{3}{*}{ Configuration 3} & $\begin{array}{l}\text { HTP Torsion, Elevator Balance \& Trim Tab Torsion } \\
\text { and Rotation (Anti-Symmetric) }\end{array}$ & Mode 76 \\
\hline & $\begin{array}{l}\text { Elevator Horn Bending, Elevator Balance \& Trim Tab } \\
\text { Rotation (Symmetric) }\end{array}$ & Mode 67 \\
\hline & Elevator Rotation (Anti-Symmetric) & Mode 17 \\
\hline
\end{tabular}


Broadbent and Clarke investigated that involvement of two tabs could cause more catastrophic effect on the flutter characteristics [5]. The report emphasized that the involvement of two tabs only cause severe effect on symmetric modes. To avoid the severe effect, it is not enough to only install spring tab and mass balanced tab, but it also needs to be noted that the tab natural frequency should be at least $50 \%$ percent higher than any relevant main structure mode.

Various research has been conducted regarding the flutter due to control surface tabs and how to prevent it. Naylor investigated that flutter due to tab should not arise if either (a) the tab is designed as such to eliminate backlash and to have an adequately stiff controlling mechanism, or (b) tab hinge should be set back to aerodynamically balanced the tab and the C.G should be on the hinge line to statically mass balanced the tab, or (c) the tab should be mass-balanced so that the C.G is on or ahead of the hinge line to increase flutter speed [11]. Collar then derived a more detailed recommendation on how the tab must be mass-balanced [6]. When the mass is in the plane of the tab, the mass should be placed at a distance forward of the tab hinge not greater than $D /(N+1)$, where $D$ is the distance between control surface the tab hinges and $N$ is the ratio of tab angle when the system is displaced but the control bloater held fixed. If the balance mass makes an angle $\theta$ with the plane of the tab, the radial distance from the mass to the hinge must not be greater than $D \cos \theta /$ $(\mathrm{N}+1)$; [6]. The optimum length of the tab balancing arm is half of $\mathrm{D} /(\mathrm{N}+1)$ or $\mathrm{D} \cos \theta /(\mathrm{N}+1)$; [6]. The variation of mass-balance on tab and control surface can give significant effects on the flutter characteristics, even though on some cases, unbalanced tab/elevator can still be safe and acceptable [17].

The investigation of flutter sensitivity to tab rotational frequency and tab bending/torsion frequency can be investigated by performing parametric analysis to determine the minimum tab rotational frequency requirement so that it can be used as reference in design process [9]. This process can be performed before natural frequencies validation (ground vibration test) being conducted, so that it could also become reference when the validation is being executed. Failure conditions in flutter evaluation should also be considered in the design and certification of an aircraft, so that all the aspects are covered. A damaged structure can result in a reduction of flutter speed which makes it more critical [18].

\section{Conclusions}

The effect of elevator tab model variation and aerodynamic hinge moment variation for flutter analysis is presented here. Structural model with more detailed tab modelling provides a more critical flutter speed result and flutter mode involving tabs. The results show that proper tab modelling has significant effect to the flutter speed. Proper modelling and parametric evaluation effort need to be performed in earlier design phase to provide necessary feedback for the design process. More study can be done to evaluate the effect from tab mass balance variation and failure conditions to the flutter characteristic.

\section{Acknowledgement}

This research was not funded by any grant.

\section{References}

[1] Indonesian Directorate General of Civil Aviation (DGCA), CASR Part 23 (Amendment 2) Airworthiness Standards: Normal, Utility, Acrobatic, and Commuter Category Airplanes, R.o.I.-M.o. Transportation, Editor. 2014: Jakarta.

[2] US Federal Aviation Administration (FAA), AC 23.629-1B: Means of Compliance with Title 14 CFR, Part 23, 23.629, Flutter, W.U.D.o.T. Advisory Circular, Editor. 2004. 
[3] Bérard, Adrien, Luca Cavagna, A. Da Ronch, Luca Riccobene, Sergio Ricci, and A. T. Isikveren. "Development and validation of a next-generation conceptual aero-structural sizing suite." In Proceedings of the 26th ICAS Congress (Anchorage, Alaska), pp. 14-19. 2008.

[4] Bhatia, Kumar G. "Airplane aeroelasticity: Practice and potential." Journal of aircraft 40, no. 6 (2003): 1010-1018. https://doi.org/10.2514/1.342

[5] Broadbent, E. G., and Mary Clarke. "Elevator flutter involving two tabs." (1954).

[6] Collar, A. R. The prevention of flutter of spring tabs. HM Stationery Office, 1943.

[7] Duncan, John S. "Pilot's handbook of aeronautical knowledge." US Department of Transportation FEDERAL AVIATION ADMINISTRATION Flight Standards Service (2016): 25-32.

[8] Komzsik, L. "MSC/NASTRAN 2001-Numerical methods Users Guide." MSC. Software Corporation (2001).

[9] Katia M. Mahasti, D042ND2009: N219 Flutter Analysis of Nominal Case Based on GVT Results, I. Aerospace, Editor. 2020: Bandung.

[10] Donald M McLean, “MSC NASTRAN Dynamic Analysis User's Guide. 2011”, Santa Ana: MSC.Software Corporation.

[11] Naylor, G. A. "Flutter of control surface tabs." (1942).

[12] William, W. P., and E. H. Johnshon. "MSC/NASTRAN Aeroelastic Analysis User's Guide (Version 68)." The MacnealSchwendler Corporation, Los Angeles (1994).

[13] Sulaeman, Erwin. Effect of compressive force on aeroelastic stability of a strut-braced wing. Virginia Polytechnic Institute and State University, 2002.

[14] USAF Test Pilot School, Flying Qualities Phase-Chapter 14: Flight Control Systems. 1988, Los Angeles: US Air Force.

[15] Wright, Jan Robert, and Jonathan Edward Cooper. Introduction to aircraft aeroelasticity and loads. Vol. 20. John Wiley \& Sons, 2008.

[16] Durmuş, Damla. "Aeroelastic analysis of variable-span morphing wing." PhD diss., Institute of Science And Technology, 2020.

[17] Čečrdle, J., and O. Vích. "Aeroelastic analysis of turboprop commuter aircraft with tip-tanks.".in 31st Congress of the International Council of the Aeronautical Sciences. (2018).

[18] Bin Abdullah, Nur Azam. "Numerical modelling and interaction of crack and aeroelastic behaviour of composite structure for aerospace applications." PhD diss., University of Sheffield, 2018. 